\title{
OPTICAL SMOKE DETECTOR: AN APPROACH TO SEMICONDUCTORS FIELD FOR HIGH LEVEL EDUCATION STUDENTS
}

\author{
Samuel Porcar-García ${ }^{1,2}$, Jaime González-Cuadra',2, Juan José Mateu ${ }^{1,2}$, Pablo \\ Serna-Gallén $^{1,2}$, María Fortuño-Morte ${ }^{1}$, Héctor Beltrán-Mir ${ }^{1,3}$, Eloísa \\ Cordoncillo ${ }^{1,3}$ \\ ${ }^{1}$ Departamento de Química Inorgánica y Orgánica. Universitat Jaume I (SPAIN) \\ ${ }^{2}$ Students from "Máster en Química Aplicada y Farmacológica, (Intensificación en Materiales \\ Avanzados)" Universitat Jaume I (SPAIN) \\ ${ }^{3}$ Lecturers of "Máster en Química Aplicada y Farmacológica" Universitat Jaume I (SPAIN)
}

\begin{abstract}
Nowadays, it is undeniable that the amount of technological devices is having a sharp increase all around us, with important benefits and repercussions for the society. Despite this, students are not used to knowing the basic principles of its operations. Hence, it is of utmost importance to approach undergraduate students to a practical example of a device they can find in their daily life.

It is a fact that science is interconnected with multiple disciplines, such as Physics and Solid State Chemistry, Materials Science and Engineering. A good example of it is a smoke detector because it combines both optical and electrical behaviour. Such a device contains a chamber inside which there is an infrared LED (light-emitting diode) and a photodiode (light detector). According to the principle of light scattering, when the smoke interrupts the path of light, it will scatter a fraction of light into the photodiode, activating the detector. Thus, detecting low levels of smoke is vital for preventing the fire expansion and occupants can get more time to escape from the premises.

The main purpose of this work is to help students to understand the work mechanism of the LED and photodiode in basis of their material composition. In order to do that, a smoke detector is disassembled and its different parts are observed. After that, the microstructure and composition of them are fully analysed by scanning electron microscopy (SEM) and energy dispersive X-ray spectroscopy (EDX) techniques. With these experiments, students have gained knowledge about semiconductors materials and got a more accurate understanding of their role in these devices.

This experience has allowed them to keep in contact during the whole study with three main concepts of Materials Science: composition, structure and properties. This fact make the work interesting not only from the point of view of students, but also for teachers of Inorganic Chemistry and Materials Science owing to its pedagogical character employing a Problem-Based Learning (PBL).
\end{abstract}

Keywords: Solid State, Inorganic Chemistry, Materials Science, Semiconductor, Photodiode, LED.

\section{INTRODUCTION}

It is a fact we belong to a globalized world, where graduated students are demanded to work in different environments in which higher-level thinking skills are required. Hence, problem-based learning $(\mathrm{PBL})$ is a longstanding educational approach that allows students to acquire new concepts to resolve problems critically and work more independently [1,2].

In order to know the basic principle operations of technological devices, PBL is applied as a useful tool for understanding some advanced concepts taught to students of a Master's Degree with further specialize in "Advanced Materials". In this work, the whole experience has been addressed in the subjects entitled "Materials for Application in Photonics" and "Materials for Electrical Applications".

Science is interconnected with multiple disciplines, such as Physics and Solid State Chemistry, Materials Science and Engineering. A good example of it is an optical smoke detector because it combines both optical and electrical behavior. Such a device contains a chamber inside which there is an infrared LED (light-emitting diode) and a photodiode (PD, light detector). Thus, with this experience, students are able to explore the working mechanism of the LED and PD in the basis of their material composition. In order to do that, a smoke detector is disassembled and the different 
parts are identified. Then, the components present in each part were characterized by the Scanning Electron Microscopy (SEM) and Energy Dispersive X-ray Spectroscopy (EDX) techniques, two of the techniques more useful in Solid State Chemistry. On the other hand, with these experiments, students gain knowledge about semiconductors materials and get a more accurate understanding of their role in these devices. Therefore, the work as a whole is interesting not only from the point of view of students but also for teachers of Inorganic Chemistry and Materials Science owing to its pedagogical character employing a PBL.

\subsection{Theory}

Optical smoke detectors are widely used for fire detection due to their simplicity and low cost. Detecting low levels of smoke is vital for preventing fire expansion and allowing occupants to get more time to escape from the premises. These detectors measure the power of scattering light as an indicator of smoke concentration and trigger fire alarms when the power of scattering light exceeds a threshold value [3]. When smoke interrupts the path of light, a fraction of it will be scattered into the PD, activating the detector, depicted in Fig. 1.

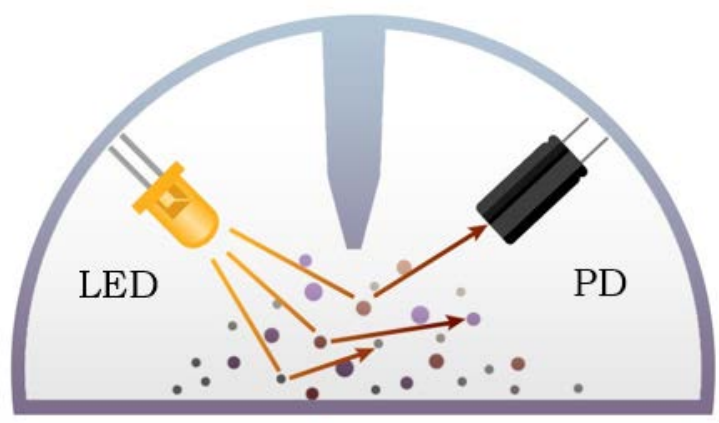

Figure 1. Scheme of light scattering in an optical smoke detector.

Microstructure and composition of the devices are fully analyzed by SEM and EDX techniques. These techniques provides topography and composition information about sample surface when a high energy electrons beam strikes it. Surface images of the materials are created by recording information of sample electrons which have been torn by the incident electron beam, these electrons are called secondary electrons. Furthermore, images are also created with information provided by incident beam electrons, which bounced off the nuclei of the sample atoms. These electrons are known as backscattered electrons.

On the other hand, the microscope is equipped with a spectrometer for energy dispersive analysis of $X$-rays (EDX) which uses $X$ radiation generated in the collision to provide information about surface composition (semiquantitative analysis) [4].

\section{METHODOLOGY}

\subsection{Time Distribution}

Nine work sessions ( $4 \mathrm{~h} /$ session) were used to complete the proposed project. The first one was used to disassemble the smoke detector and the following three sessions were employed to perform the scanning electron microscopy (SEM) analysis. Finally, in a period of five sessions, students made a complete report of the results with exhaustive bibliographic research and with the help of their teachers.

\subsection{Disassembly of the Smoke Detector}

The main aim of this experiment is to understand the parts of a smoke detector. Therefore, students started disassembling a commercial detector step by step. They could observe the initial aspect of the detector, Fig. 2(a), and after removing the plastic case, it was found a metallic grid that protects the detector against dust particles, Fig. 2(b). Once this grid was removed, the optical system of the detector which contains the LED and PD was located as can be seen in Fig. 2(c). Moreover, in Fig. 2 (d) it is depicted the electronic system which is connected to the optical one and controls the 
functioning of the whole detector. Students recognized several devices present in the electronic system, which were studied in the subject "Materials for Electrical Applications". The transparent LED and the black PD, shown in Fig. 2(e-f) respectively, were disassembled to perform a later analysis of the elements that constitute these devices.

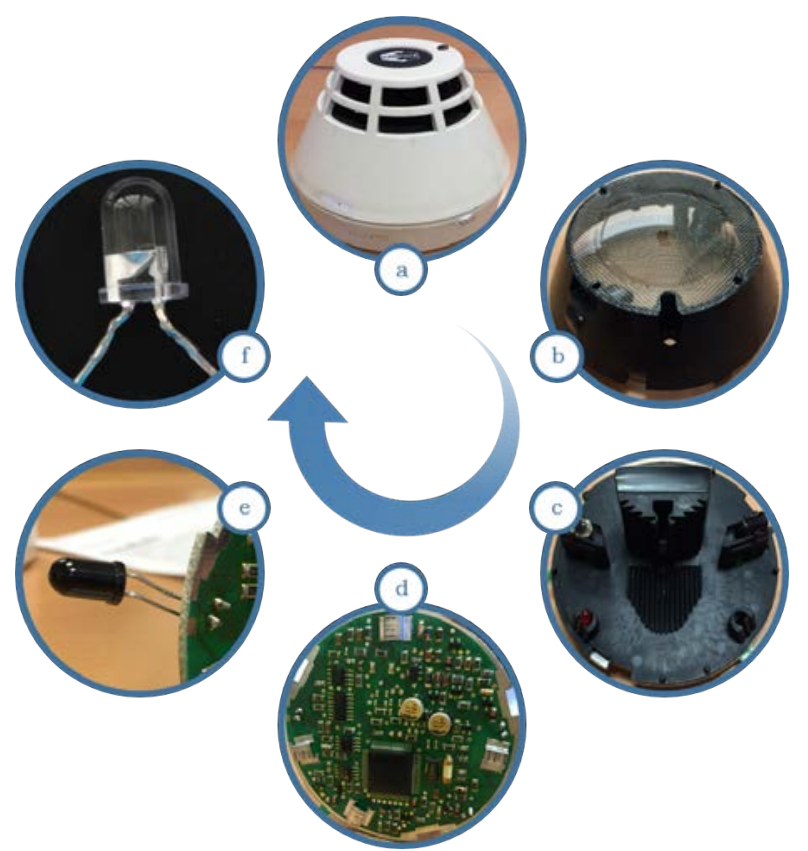

Figure 2. Disassembly of the smoke detector showing: smoke detector case (a), metallic grid (b), optical system (c), electronic circuit (d), photodiode (e) and LED (f).

\subsection{Experimental Analysis}

In the first session of SEM analysis, students focused on the study of LED components, while in the following two sessions they observed the different parts of PD, enabling them to learn the basics of SEM technique. The microstructure of samples was observed using a JEOL $7001 \mathrm{~F}$ scanning electron microscope equipped with a spectrometer for energy dispersive analysis of X-rays, which allowed to determine the composition of samples. The operation parameters were: an acceleration voltage of $15 \mathrm{kV}$, a measuring time of $20 \mathrm{~s}$ and a working distance between 10 and $13 \mathrm{~mm}$.

\section{RESULTS}

\subsection{LED Analysis}

LED was carefully disassembled to avoid the different components could get damaged. Students found four main pieces, which were fully identified according to the literature. Figs. 3(a-b) correspond to cathode and anode, respectively. A thin wire whose micrograph is showed in Fig. 3(c) connects them. The micrograph shown in Fig. 3(d) corresponds to the semiconductor material. The different atomic concentrations of the different parts of these components (points 1 to 6) were extracted from EDX spectra, and summarized in Table 1.

Table 1. Atomic concentrations for each point shown in SEM micrographs of Figure 3.

\begin{tabular}{c|c|c|c|c|c|c|c|c|c|c|c}
\hline \hline Point & 1 & 2 & \multicolumn{2}{|c|}{3} & \multicolumn{4}{|c|}{4} & 5 & \multicolumn{2}{|c}{6} \\
\hline Element & $\mathrm{Ag}$ & $\mathrm{Ag}$ & $\mathrm{Ag}$ & $\mathrm{Au}$ & $\mathrm{Al}$ & $\mathrm{P}$ & $\mathrm{Ga}$ & $\mathrm{As}$ & $\mathrm{Au}$ & $\mathrm{Ag}$ & $\mathrm{Au}$ \\
\hline Atomic $\%$ & 100 & 100 & 26.8 & 73.2 & 15.7 & 15.2 & 29.3 & 39.8 & 100 & 28.5 & 71.5 \\
\hline \hline
\end{tabular}




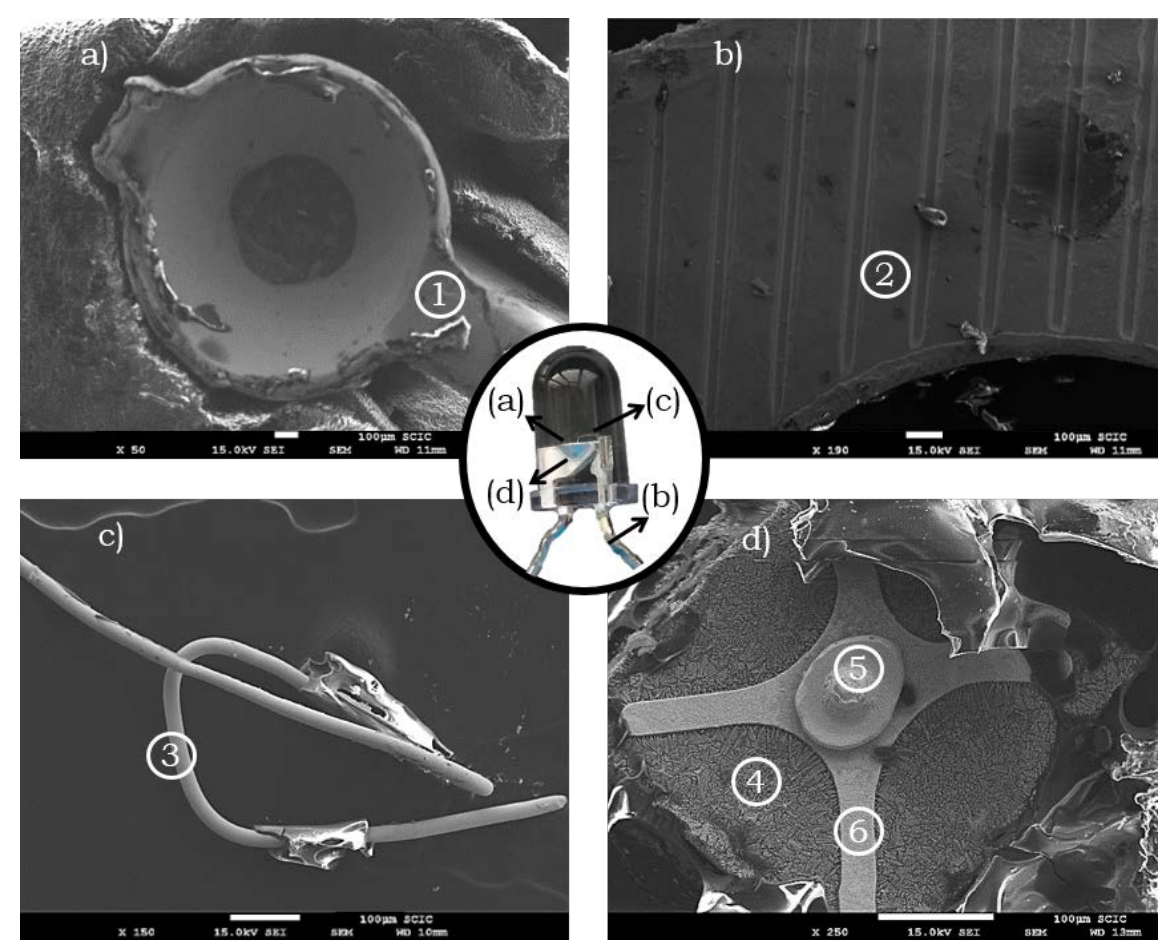

Figure 3. SEM micrographs of the different LED pieces: cathode (a), anode (b), wire (c) and semiconductor material (d).

\subsubsection{Understanding the Structure and Composition of the LED}

After the topographic and composition analysis of the LED constituents, students reached the conclusion that the LED device is composed of four main parts, which are depicted in Fig. 4. The main pieces are cathode and anode, both composed of $\mathrm{Ag}$ and linked by a gold/silver alloy wire through a semiconductor material, which is placed in a depression of the cathode.

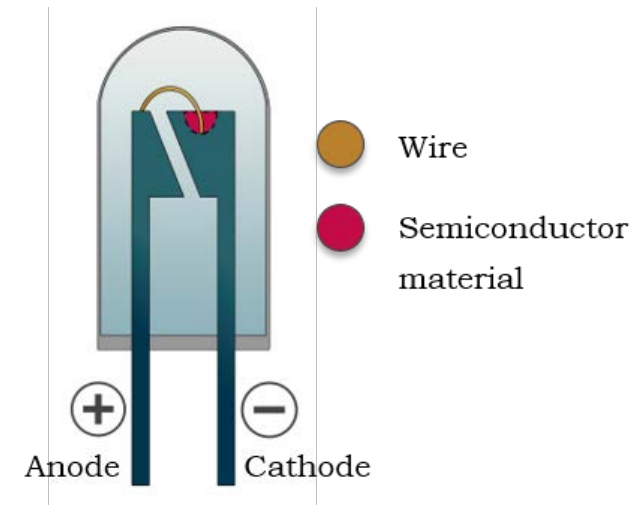

Figure 4. Representation of the LED structure.

After that, students could extend knowledge about LED and semiconductor materials by asking some questions themselves.

\section{+ Question 1: Which kind of LED is it?}

Answer 1: After performing EDX spectroscopy to the semiconductor piece, Fig. 3(d), it revealed that this piece is composed by As, $\mathrm{Al}$, and $\mathrm{Ga}$. This mixture corresponds to an $\mathrm{Al}_{x} \mathrm{Ga}_{1-\mathrm{x}} \mathrm{As} / \mathrm{GaAs}$ material system doped with $P$, having a band gap corresponding to the IR region. There are several strategies for AlAsGa-based IR LEDs, such as $\mathrm{Al}_{x} \mathrm{Ga}_{1-\mathrm{x}} \mathrm{As}$ bulk active regions or $\mathrm{Al}_{\mathrm{x}} \mathrm{Ga}_{1-\mathrm{x}} \mathrm{As} / \mathrm{GaAs}$ quantum well active regions, but it is not possible to determine the strategy used in this LED only with SEM and EDX data [5]. 


\section{+ Question 2: How light is generated?}

Answer 2: The semiconductor material is composed by an n-type semiconductor (which introduces an electron band just below the conduction band) and a p-type semiconductor (which introduces a hole band just above the valence band). $\mathrm{N}$-type and $\mathrm{p}$-type semiconductors are combined forming a $\mathrm{p}$ - $\mathrm{n}$ junction, with a particular energy band gap. When current crosses the $p-n$ junction, an electron is combined with a hole generating a photon with the same energy as the band gap (light emission) [6].

\section{+ Question 3: How electrodes are connected to the semiconductor?}

Answer 3: Current flows from the negative terminal (cathode) of the LED into the n-type semiconductor and back out the p-type semiconductor to the positive terminal (anode) of the LED [6].

\subsection{Photodiode Analysis}

PD was disassembled and students extracted a small black plate whose main components were identified, Fig. 5. They could observe the different compositions of each PD part, which will be discussed in the following section. From EDX spectra, the different atomic concentrations of samples were extracted and summarized in Table 2.

Table 2. Atomic concentrations for each point shown in SEM micrographs of Figure 5.

\begin{tabular}{c|c|c|c|c|c|c|c|c|c}
\hline \hline \multirow{2}{*}{ Point } & 1 & \multicolumn{2}{|c|}{2} & \multicolumn{3}{c|}{3} & \multicolumn{3}{|c}{4} \\
\hline Element & $\mathrm{Ag}$ & $\mathrm{Al}$ & $\mathrm{Si}$ & $\mathrm{N}$ & $\mathrm{Al}$ & $\mathrm{Si}$ & $\mathrm{O}$ & $\mathrm{Al}$ & $\mathrm{Si}$ \\
\hline Atomic $\%$ & 100 & 97.1 & 2.9 & 32.4 & 0.5 & 67.1 & 61.9 & 0.4 & 37.7 \\
\hline \hline
\end{tabular}
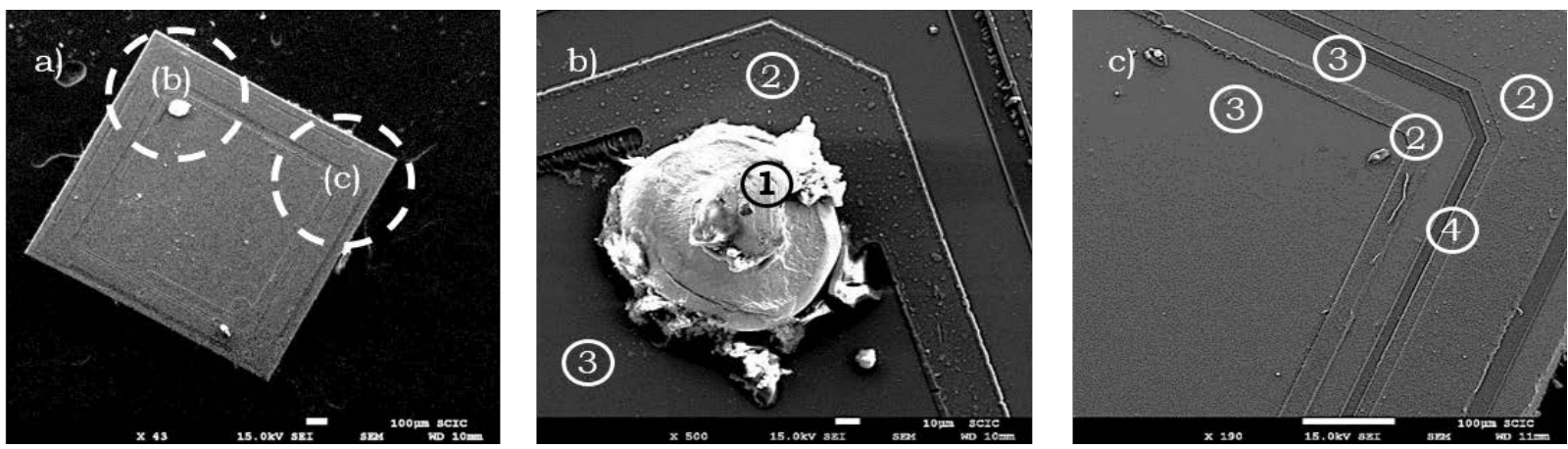

Figure 5. PD micrographs: PD plate (a) and zooms of electrode contact (b) and plate (c).

\subsubsection{Understanding the Structure and Composition of the LED}

After analyzing the structure and composition of the PD parts, students made a thorough literature search and concluded that the commercial PD was actually a combination of a metal-semiconductor-metal photodetector (MSM PD) integrated with a silicon-on-insulator (SOI) waveguide. The semiconductor material was $\mathrm{SiN}_{\mathrm{x}}$, the two metals used as electrodes were $\mathrm{Au}$ and $\mathrm{Al}$ and the insulator was $\mathrm{SiO}_{2}$. $\mathrm{An}$ illustrative representation of the PD structure observed by SEM can be appreciated in Fig. 6.

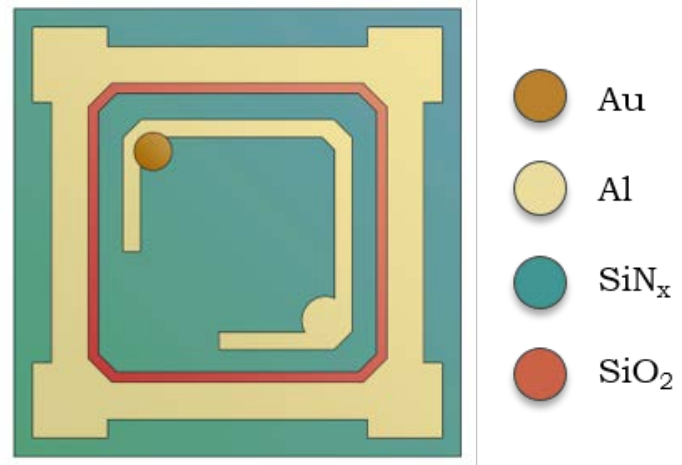

Figure 6. Representation of the photodiode structure. 
Then, students established the theoretical background of this device. They were able to deepen in the semiconductors field of study by seeking out answers to some questions raised:

\section{+ Question 1: Why an SOI waveguide is used in the PD?}

Answer 1: An optical waveguide is a dielectric structure that transports energy at wavelengths in the infrared or visible regions of the electromagnetic spectrum, with minimum loss of energy. In the PD, the SOI used as waveguide was $\mathrm{SiO}_{2}$ because of its high dielectric constant [7].

\section{+ Question 2: How an MSM PD works?}

Answer 2: An MSM PD consists of two metal electrodes generating two Schottky barriers. A free semiconductor surface forms the active region in which light will be absorbed. In our system, the light is emitted by the LED and the scattered by smoke [8].

If a bias voltage is applied between the electrodes (one Schottky barrier is reverse-biased and the other is forward-biased), a space charge region (SCR) of increased width is produced. A photon with an energy greater than the band gap of the semiconductor can be absorbed by an electron near the reverse-biased barrier. Then, it is excited from the valence band to the conduction band, creating electron-hole pairs, Fig. 7. These pairs are separated under the effects of the electric field present in the SCR, resulting in an electronic output signal. The forward-biased electrode simply acts as a collection electrode $[7,9]$.

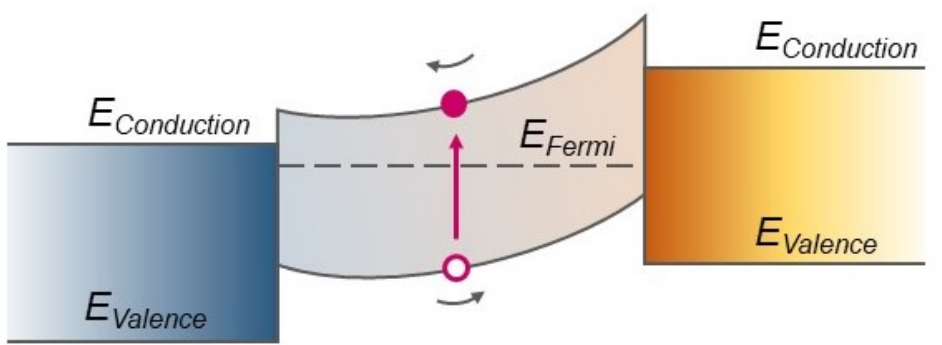

Metal $1 \quad$ Semiconductor Metal 2

Figure 7. Energy band diagram of an MSM PD.

\section{+ Question 3: Why different metals are used?}

Answer 3: In the commercial PD, different metals ( $\mathrm{Au}$ and $\mathrm{Al}$ ) are used for electrodes in order to optimize the barrier heights and reduce the dark current. Another way to enhance the responsivity of the PD is reached by having a small Au electrode area, as it can be seen in Fig. 5.

\section{+ Question 4: Why SiN $_{x}$ is used instead of Si?}

Answer 4: $\mathrm{SiN}_{\mathrm{x}}$ layers are used as very effective antireflective coatings, thus enhancing the detector response [10].

\section{CONCLUSIONS}

The work developed in this paper has allowed students to relate day to day chemistry with theoretical concepts learned in the Master's Degree subjects. In this project, the PBL methodology was employed to study a smoke detector, which combines electrical and optical devices. Not only this practice has shed some light on a different point of view about learning, but it has also boosted up students' knowledge of semiconductor materials.

\section{ACKNOWLEDGEMENTS}

We would like to thank the "Máster en Química Aplicada y Farmacológica" of the Universitat Jaume I of Castellón. 


\section{REFERENCES}

[1] A.B. Flynn, R. Biggs, "J. Chem. Educ.," The Development and Implementation of a Iroblem-Based Learning Format in a Fourth-Year Undergraduate Synthetic Organic and Medicinal Chemistry Laboratory Course, vol. 89, pp.52-57, 2012.

[2] C. Diawati, Liliasari, A.Setiabudi, Buchari, "J. Chem. Educ.," Using Project-Based Learning To Desing, Build, and Test Student-Made Photometer by Measuring the Unknown Concentration of Colored Substances, vol. 95, pp. 468-475, 2018.

[3] J. Shi, Optical smoke detector, Master's Thesis, pp. 13-22, Tallinn/Estonia: Tallinn University of Technology, 2018.

[4] D.A. Skoog, F.J. Holler, S.R. Crouch, Principles of instrumental Analysis, pp. 608-617, Belmont, USA, Thomson Brooks/Cole, 2007.

[5] E.F. Schubert, Light-Emitting Diodes, pp. 155-177, Cambridge, United Kingdom, Cambridge University Press, 2003.

[6] E.P. Wagner, "J. Chem. Educ.," Investigating Bandgap Energies, Materials, and Design of LightEmitting Diodes, vol. 93, pp. 1289-1298, 2016.

[7] F. Omnes, Introduction to semiconductor detectors, in Optoelectronic Sensors, Decoster, D. (ed.), Harari, J. (ed.), pp. 1-14, Wiley-ISTE Ltd, United States, 2009.

[8] M. Casalino, M. Iodice, L. Sirleto, I. Rendina, G. Coppola, "Optical society of America," Asymmetric MSM sub-bandgap all silicon photodetector with low dark current, vol. 21, pp. 2807228082, 2013.

[9] F. Haas, Metal-semiconductor-metal photodetectors for optical interconnect applications, Ed. Rome Laboratory: Rome (New York), New York, United States, pp 7-10, 1997.

[10] M. Lipinski, "Archives of Materials Science and Engineering," Silicon nitride for photovoltaic application, vol. 46, pp. 69-87, 2010. 